\title{
China's fiscal decentralization and environmental quality: theory and an empirical study - Erratum
}

Yu Hao, Yu-Fu Chen, Hua Liao, and Yi-Ming Wei

https://doi.org/10.1017/S1355770X19000263, Published by Cambridge University Press, 02 September 2019

Keywords: China; economic growth; environmental quality; fiscal decentralization; panel data; erratum

When originally published, the article contained some errors with the author names in the Cite this Article section. A footnote has been added to the article in question to reflect this correction.

The error was made by the publisher during the production process, for which we apologise.

\section{Reference}

Hao Y, Chen Y F, Liao H and Wei Y M (2020) China's fiscal decentralization and environmental quality: theory and an empirical study. Environment and Development Economics 25, 159-181. https://doi.org/ $10.1017 /$ S1355770X19000263 